\title{
Molecular Cloning and Functional Expression of the Potassium- Dependent Sodium-Calcium Exchanger from Human and Chicken Retinal Cone Photoreceptors
}

\author{
Clemens F. M. Prinsen, Robert T. Szerencsei, and Paul P. M. Schnetkamp \\ Department of Physiology and Biophysics and the Medical Research Council Group on Ion Channels and Transporters, \\ University of Calgary, Faculty of Medicine, Calgary, Alberta, Canada T2N 4N1
}

\begin{abstract}
Light causes a rapid lowering of cytosolic free calcium in the outer segments of both retinal rod and cone photoreceptors. This light-induced lowering of calcium is caused by extrusion via a $\mathrm{Na}-\mathrm{Ca}$ exchanger located in the rod and cone outer segment plasma membrane and plays a key role in the process of light adaptation. The $\mathrm{Na}-\mathrm{Ca}$ exchanger in retinal rod outer segment was shown earlier to be a novel $\mathrm{Na}-\mathrm{Ca}+\mathrm{K}$ exchanger (NCKX), and its cDNA was obtained by molecular cloning from several mammalian species. On the other hand, the proper identity of the retinal cone $\mathrm{Na}-\mathrm{Ca}$ exchanger, in terms of both functional characteristics (e.g., requirement for and transport of potassium) and molecular identity, has not yet been elucidated. Here, we report the molecular cloning, intraretinal localization by in situ hybridization, and initial functional characterization of the chicken and human cone-specific $\mathrm{Na}-\mathrm{Ca}$ exchangers. In
\end{abstract}

addition we report the chicken rod-specific NCKX. We identified NCKX transcripts in both human and chicken cones and observed strong potassium-dependent $\mathrm{Na}-\mathrm{Ca}$ exchange activity after heterologous expression of human and chicken cone NCKX cDNAs in cultured insect cells. In situ hybridization in chicken retina showed abundant rod NCKX transcripts only in rod photoreceptors, whereas abundant cone NCKX transcripts were found in most, if not all, cone photoreceptors and also in a subpopulation of retinal ganglion cells. A detailed comparison with the previously described retinal rod and brain NCKX cDNAs is presented.

Key words: sodium-calcium exchange; retina; photoreceptor cells; ganglion cells; chicken; human; calcium homeostasis; in situ hybridization
The outer segments of both retinal rod and cone photoreceptors have been shown to contain an electrogenic $\mathrm{Na}-\mathrm{Ca}$ exchanger (Yau and Nakatani, 1984; Lagnado et al., 1988; Nakatani and Yau, 1989). In darkness, the $\mathrm{Na}-\mathrm{Ca}$ exchanger extrudes calcium that enters rod or cone outer segments via the cGMP-gated channels, whereas in bright light the exchanger mediates a rapid lowering of cytosolic free calcium concentration in both rod (McNaughton et al., 1986; Gray-Keller and Detwiler, 1994; Sampath et al., 1998) and cone outer segments (Sampath et al., 1999). Both the kinetics and the magnitude of the light-induced decrease in free calcium concentration in cone outer segments are considerably faster compared with those measured in rod outer segments (Sampath et al., 1998, 1999), in agreement with earlier, more indirect measurements which suggested that for similar

\footnotetext{
Received Sept. 7, 1999; revised Nov. 22, 1999; accepted Nov. 24, 1999.

This work was supported by operating grants from the Medical Research Council of Canada (MRC) to P.P.M.S. and to the MRC Group on Ion Channels and Transporters, and the Canadian RP Foundation (P.P.M.S.) and by the Alberta Heritage Foundation for Medical Research (AHFMR). C.F.M.P. is a recipient of an AHFMR fellowship; P.P.M.S. is an AHFMR Medical Scientist. We thank Dr. U. B. Kaupp (Forschungszentrum Jülich, Institut für Biologische Informationsverarbeitung, Jülich, Germany) for his kind gift of the chicken retinal cDNA libraries, Drs. P. J. Farrell and K. Iatrou (Department of Biochemistry and Molecular Biology, University of Calgary) for providing the insect transfection vector pIE1/153A, Dr. D. Rancourt for use of the paraffin mounting equipment and microtome, and Dr. W. K. Stell for discussion of the in situ hybridization results.

Sequence data from this study have been deposited with the GenBank/European Molecular Biology Laboratory Data Libraries under accession numbers AF097366 and AF177984-AF177987.

Correspondence should be addressed to Dr. Paul P. M. Schnetkamp, University of Calgary, Faculty of Medicine, 3330 Hospital Drive N.W., Calgary, Alberta, Canada T2N 4N1. E-mail: pschnetk@ucalgary.ca.

Copyright (C) 2000 Society for Neuroscience $0270-6474 / 00 / 201424-11 \$ 15.00 / 0$
}

changes in outer segment $\mathrm{Na}-\mathrm{Ca}$ exchange current, changes in outer segment calcium concentration are larger and faster in cones than in rods (for review, see Korenbrot, 1995).

The retinal rod $\mathrm{Na}-\mathrm{Ca}$ exchanger protein was shown to be a $\mathrm{Na}-\mathrm{Ca}+\mathrm{K}$ exchanger (NCKX) that uses both the inward sodium gradient and the outward potassium gradient to drive calcium extrusion (Cervetto et al., 1989; Schnetkamp et al., 1989). Rod NCKX1 cDNA has been cloned from three mammalian species: bovine (Reiländer et al., 1992), human (Tucker et al., 1998a), and dolphin (Cooper et al., 1999). A related NCKX2 cDNA was recently cloned from rat brain (Tsoi et al., 1998). Both dolphin rod NCKX1 and rat brain NCKX2 were shown to code for a potassium-dependent $\mathrm{Na}-\mathrm{Ca}$ exchanger after heterologous expression in human embryonic kidney (HEK) 293 cells. Both NCKX1 and NCKX2 are distantly related to the gene family of the more common potassium-independent $\mathrm{Na}-\mathrm{Ca}$ exchangers (NCX) (Schwarz and Benzer, 1997) [for a recent review on NCX, see Blaustein and Lederer (1999)].

Immunohistochemistry on the bovine retina was use to locate bovine rod NCKX1 exclusively to the outer segment plasma membrane, whereas no significant amounts of NCKX1 were detected in rod disk membranes, in rod inner segments, or in cone photoreceptors (Haase et al., 1990; Reid et al., 1990; Kim et al., 1998). Thus, the molecular identity of the $\mathrm{Na}-\mathrm{Ca}$ exchanger responsible for calcium extrusion in cone outer segments has not been identified yet, nor has it been determined whether the $\mathrm{Na}-\mathrm{Ca}$ exchanger in cones is of the NCX or NCKX type. To identify the cone $\mathrm{Na}-\mathrm{Ca}(+\mathrm{K})$ exchanger(s), we used the chicken retina as a model, because birds are known to have conedominated retinas with cones accounting for up to $85 \%$ of photo- 
receptors (Morris, 1970; Ramon y Cajal, 1972), whereas most mammals have rod-dominated retinas. We have isolated and sequenced two distinct chicken retinal NCKX cDNAs and localized their transcripts in the inner segments of rod and cone photoreceptors, respectively. Subsequently, we obtained the human cone NCKX cDNA as well. Potassium-dependent $\mathrm{Na}-\mathrm{Ca}$ exchange was observed for the chicken rod and for both human and chicken cone NCKX proteins after heterologous expression in cultured insect cells.

\section{MATERIALS AND METHODS}

Animals. Chicks (male White Leghorns, Gallus gallus domesticus) were obtained from a local hatchery (Lillydale Hatchery, Linden, Alberta) and housed in the Animal Care Facilities under $12 \mathrm{hr}$ light/dark conditions, with access to water and food ad libitum. Heads from adult chicken were obtained from a local slaughterhouse.

Preparation of RNAs and $c D N A s$. Total RNA from human retinal tissue (obtained from the Lions Eye Bank Alberta at the Rockyview General Hospital, Calgary), human hippocampus, chicken retinas, and chicken brain was prepared by homogenization in TRIzol reagent (Life Technologies, Burlington, Ontario) and processed according to the manufacturer's protocol. Samples were subsequently treated with RQ1 RNasefree DNase (Promega Corporation, Madison, WI) and purified by standard organic extraction, followed by ethanol precipitation. Firststrand cDNAs were synthesized from retinal total RNA $(2.5 \mu \mathrm{g})$ with Superscript II reverse transcriptase (Life Technologies), using either oligo-dT ${ }_{12-18}$ (Amersham Pharmacia Biotech, Baie d’Urfé, Québec) or random hexanucleotides as primers for synthesis according to the manufacturer's protocol. First-strand cDNAs were purified on PCR spin columns (Qiagen, Mississauga, Ontario) according to the manufacturer's directions and diluted up to $200 \mu \mathrm{l}$ with $10 \mathrm{~mm}$ Tris-HCl, $\mathrm{pH}$ 8.5. Two microliters of the first-strand cDNA were used in $20 \mu \mathrm{l}$ PCR reactions.

cDNA library screen for chicken $N C K X$. Two chicken retinal cDNA libraries in lambda ZAP II vector were used: one made with oligo-dTprimed cDNA and one made with random-primed cDNA (Bönigk et al., 1993). As probe we used a PCR product of primers TGAAGAGCCTCTGTCCCTGGACTGGC and TCAGACAGATACAGGACAGGATAT on bovine rod NCKX1 cDNA, amplifying a 621 nucleotide (nt) fragment. The probe was random-primed labeled with $\left[\alpha^{-32} \mathrm{P}\right] \mathrm{dCTP}$ (Prime-It II Random Primer Labeling Kit, Stratagene, La Jolla, CA). Approximately $3 \times 10^{5}$ clones of each library were screened using the conserved (621 nt) bovine NCKX1 cDNA fragment as probe under medium stringency (100 mM sodium phosphate, $\mathrm{pH} 7.2,0.1 \%$ SDS at $65^{\circ} \mathrm{C}$ ). Eighty-nine primary positive clones were isolated, from which 13 were further characterized by in vivo excision with ExAssist helperphage (Stratagene) and analyzed by direct sequencing (Thermosequenase, Amersham Pharmacia Biotech). Thirty-two of the 89 primary positive clones were examined for alternative splicing variants by PCR screening with the following primer sets: CTCATCCTGTTTTTCCTAGACAGC and ACCTGATGAGCCCACCACACCA for rod NCKX-specific amplification and GTGCGGTGATACTCCATGTAATTG and TGAGCGGCTGGTCCTCGTCCTCT for cone NCKX-specific amplification. PCR products were separated by electrophoresis on $1 \%$ agarose/Tris-acetate/ EDTA gels. All oligonucleotides were synthesized on an Oligo 1000 DNA Synthesizer (Beckman Instruments, Mississauga, Ontario). Nucleotide sequences were analyzed using the computer program Generunner 3.0; DNA and amino acid sequence alignments were made using ClustalW 1.7 and Boxshade 3.21, both available from the Internet (http://dot.imgen. bcm.tmc.edu:9331/multi-align/multi-align.html), and database searches using gapped BLAST (BLAST version 2.0) available from the NCBI Internet homepage (http://www.ncbi.nlm.nih.gov/).

Molecular cloning of the human cone NCKX $c D N A$. Using sets of primers derived from the chicken cDNA, PCR amplification was performedonrandom-primedhumanretinacDNA(primersetsAGGAACAGCATCTTCCAGCTCATG and TTTGTTCATCCTCCACTTGCAG; GAATGATTTACATGTTCATAGCCTTAGC and CACATGACATTTCTTCTTGGCG; GAATGATTTACATGTTCATAGCCTTAGC and TTTGTTCATCCTCCACTTGCAG). DNA sequence analysis was performed using the thermosequenase kit (Thermosequenase, Amersham Pharmacia Biotech). Subsequently, the $5^{\prime}$ and $3^{\prime}$ rapid amplification of cDNA ends (RACE) technique was used to identify the cDNA ends of the partial human cDNA. The first-strand cDNAs, as described in Preparation of RNAs and cDNAs, were used. A poly(A) tail was added using terminal deoxynucleotide transferase (10 U; Life Technologies) in the presence of $1 \mathrm{~mm}$ dATP for $10 \mathrm{~min}$ at $37^{\circ} \mathrm{C}$. Second-strand synthesis was performed in the same way, except that the synthetic anchor primer TGACTGGACTATGGTCTCGACATGGCGTAGTCG(T) ${ }_{18}$, instead of oligo-dT, was used as the primer. First-round PCR was performed using the $5^{\prime}$ anchor-specific primer GGGTGACTGGACTATGGTCT and a cDNA-specific primer AGGAAGTTTTTTCCCATCACGTTCT complementary to positions $1548-1572$ of the complete human cone NCKX nucleotide sequence. PCR was performed in standard buffers with $50 \mathrm{ng}$ of double-stranded cDNA, with an annealing temperature of $60^{\circ} \mathrm{C}$ for 35 cycles of $90 \mathrm{sec}$ extension each. Second-round PCR (3' RACE) was performed with the $3^{\prime}$ anchor-specific primer GGGCTCGACATGGCGTAGTC and TCACGTTCTTTGGCTCCATTACC, a cDNA-specific primer complementary to positions 1564-1586 of the sequence, with $0.1 \mu \mathrm{l}$ of the first-round product as template, for 35 cycles using the same PCR conditions. A band of $\sim 1.5 \mathrm{~kb}$ was observed after agarose gel electrophoresis of the second-round PCR products. This band was gel-isolated, sequenced, and found to contain the complete $3^{\prime}$ coding sequence of the cDNA as well as $3^{\prime}$ flanking sequences. $5^{\prime}$ R ACE was performed with primers AAACCACATAGCAAAAATAAGCTGTT (position 872-897) and nested primer GAGAAGCAAGCTTTCCCACCACAT (position 846-869) and the anchor-specific primer. 5' RACE products of 500-1000 nt were gel-isolated and direct-sequenced.

Northern blot analysis. Tissues and cell lines were used to extract total RNA using the TRIzol reagent (Life Technologies). Equal amounts of total RNAs (based on optical density at $260 \mathrm{~nm}$ ) were analyzed on $1 \%$ agarose/formaldehyde gels, and RNAs were transferred to Hybond N+ membranes (Amersham Pharmacia Biotech). Northern hybridization was performed using randomly labeled $\left[\alpha-{ }^{32} \mathrm{P}\right] \mathrm{dCTP}$-labeled cDNA probes (Prime-It II Random Primer Labeling Kit) in ExpressHyb hybridization solution (Clontech laboratories, Palo Alto, CA) at $68^{\circ} \mathrm{C}$. A human normal brain mRNA blot loaded with mRNAs from the frontal lobe, temporal lobe, parietal lobe, occipital lobe, cerebellum, and lung (Northern Territory, Act-N, Invitrogen, Carlsbad, CA) was used according to the manufacturer's directions.

Tissue dissection, fixation, and sectioning. Between 7 and $10 \mathrm{~d}$ after hatching, chicks were killed by chloroform inhalation. Eyes were removed from the orbit, and most of the attached connective tissues and muscles were trimmed away. Eyes were hemisected equatorially, and the gel vitreous was removed from the posterior eye cup. Eye cups were fixed for $24 \mathrm{hr}$ at $4^{\circ} \mathrm{C}$ in buffered neutral formalin (10\%) (BDH, Toronto, Ontario). Fixed samples were washed three times in PBS $(0.05 \mathrm{M}$ phosphate buffer and $195 \mathrm{~mm} \mathrm{NaCl}, \mathrm{pH} 7.4$ ), dehydrated in a graded ethanol series, and embedded in paraffin. Vertical sections $(5 \mu \mathrm{m})$ were mounted on Micro Slides Superfrost Plus slides (VWR Canlab, Mississauga, Ontario), dried at room temperature for $18 \mathrm{hr}$, and stored at $-20^{\circ} \mathrm{C}$.

$c R N A$ probes. The full-length chicken rod NCKX and cone NCKX cDNAs in Bluescript were linearized using NotI and HindIII (rod NCKX) and BamHI and Acc65I (cone NCKX) (New England Biolabs, Mississauga, Ontario) for in vitro transcription using T7 and T3 RNA polymerase, respectively. A $860 \mathrm{nt}$ chicken rhodopsin cDNA cloned in Bluescript was used to make antisense and sense probes using T3 and T7 RNA polymerase, respectively. Transcription reactions were performed according to the manufacturer's instructions using either T7 or T3 RNA polymerase in the presence of 11-digoxygenin UTP [DIG RNA labeling kit (SP6/T7), Boehringer Mannheim, Laval, Québec]. The yields of the labeling products after purification were quantified using dot-blotting and agarose gel electrophoresis.

In situ hybridization. The RNA in situ hybridization method was performed as described (Schaeren-Wiemers and Gerfin-Moser, 1993; Breitschopf and Suchanek, 1996). Briefly, sections were hybridized with probe $(400 \mathrm{ng} / \mathrm{ml})$ in $50 \%$ formamide $/ 5 \times$ sodium chloride-sodium citrate-phosphate (SSCP) $/ 40 \mu \mathrm{g} / \mathrm{ml}$ salmon sperm DNA for $18 \mathrm{hr}$ at $65^{\circ} \mathrm{C}$ under parafilm (American National Can, Chicago, IL). Posthybridization washes were two in $2 \times \mathrm{SSCP}$ for a total of $30 \mathrm{~min}$ at $65^{\circ} \mathrm{C}$; and two in $0.2 \times \mathrm{SSCP}$ for a total of $1 \mathrm{hr}$ at $65^{\circ} \mathrm{C}$. Incubation with $\mathrm{Fab}$ fragments from an anti-digoxigenin antibody (1:5000) from sheep, conjugated with alkaline phosphatase (Boehringer Mannheim, Indianapolis, IN) for $2 \mathrm{hr}$ at $22^{\circ} \mathrm{C}$ was used for the detection of the digoxigenin-labeled riboprobes. Precipitation of the reaction products of nitroblue tetrazolium/5-bromo4-chloro-3-indolyl phosphate (Life Technologies) was allowed for 3-5 d, with a daily change of substrate solution. Slides were mounted with Glycergel (Dako, Mississauga, Ontario). Results were documented with Elite Chrome 160 Thungsten (Eastman Kodak, New Haven, CT) at ASA 160.

Construction of the pIE1/153A-chicken cone and rod NCKX, and human 
cone NCKX vectors. Full-length chicken rod and cone NCKX and the alternative spliced cone NCKX cDNAs were cut out of their original vectors pBluescript with the restriction enzyme EcoRI, blunt-ended with DNA polymerase I, large (Klenow) fragment (Life Technologies), and gel-isolated (QIAquick Gel Extraction Kit, Qiagen). The vector pIE1/ 153A (Lu et al., 1997) was digested with SmaI, treated with Calf Intestinal Alkaline Phosphatase (Life Technologies), and purified on PCR spin columns (Qiagen). Ligations were performed according to the manufacturer's protocol (Rapid DNA ligation kit, Boehringer Mannheim). The orientation of the cDNAs was verified by sequencing vector/ insert boundaries. Unique BstX1 and $E c o \mathrm{~N} 1$ restriction sites in the pIE1/153A-cone NCKX clones were used to replace a 1442 nt partial cone NCKX cDNA fragment with the 1493 nt BstX1-EcoN1 fragment of the full-length cone NCKX cDNA, as a control for differences in uncoding regions between the two cone NCKX cDNAs. Both the full-length human cone NCKX and its splice variant were inserted in the same insect expression vector pIE1/153A using SmaI and BamHI restriction sites, and clones were checked for correct orientation as above.

Stable expression of rod and cone NCKX in insect cells. A novel lepidopteran insect cell expression system was used to establish stable transfected BTI-TN-5B1-4 cells (High Five, Invitrogen) insect cells (Farrell et al., 1998). Stable transfected cell lines were generated when High Five cells were initially cotransfected with two vectors: one expression plasmid containing the various NCKX cDNAs and the second plasmid conferring resistance to hygromycin B using lipofectin (Life Technologies) as transfection reagents. After $2 \mathrm{~d}$ the transfection was followed by antibiotic selection in $1.0 \mathrm{mg} / \mathrm{ml}$ hygromycin B and establishment of positive clonal cell lines. High Five cells were subcultured at $28^{\circ} \mathrm{C}$ in IPL-41 insect medium (Life Technologies) supplemented with $0.2 \mathrm{gm} / 1 \mathrm{~L}$-glutamine, $1.0 \mathrm{gm} / 1 \mathrm{D}$-glucose, $10 \%$ heat-inactivated fetal bovine serum (Life Technologies), and penicillin-streptomycin-fungizone (Life Technologies). As a control for mRNA expression, the total RNAs of several clonal cell lines were isolated, and Northern hybridization with the chicken rod or cone NCKX cDNA as probe was performed.

Measurement of ${ }^{45} \mathrm{Ca}^{2+}$ uptake. Potassium-dependence of calcium uptake was measured in High Five cells after stable transfection with the full-length rod chicken NCKX cDNA and the full-length and alternative spliced chicken and human cone NCKX cDNA. Cells were loaded with sodium by incubation for $15 \mathrm{~min}$ in $150 \mathrm{~mm} \mathrm{NaCl}, 80 \mathrm{~mm}$ sucrose, $20 \mathrm{~mm}$ HEPES, pH 7.4, $0.2 \mathrm{~mm}$ EDTA, and $2.5 \mu \mathrm{M}$ monensin (Sigma-Aldrich, Oakville, Ontario). The cation exchange ionophore monensin was subsequently removed by washing twice in the above medium without monensin, but containing $1 \%$ BSA, followed by washing twice in medium in which $\mathrm{LiCl}$ replaced $\mathrm{NaCl}$ (Schnetkamp et al., 1995). The final cell pellet was resuspended in $150 \mathrm{~mm} \mathrm{LiCl,} 80 \mathrm{~mm}$ sucrose, $20 \mathrm{~mm}$ HEPES, pH 7.4, and $0.05 \mathrm{~mm}$ EDTA and left at $25^{\circ} \mathrm{C}$ until use. ${ }^{45} \mathrm{Ca}^{2+}(0.5-1.0$ $\mu \mathrm{Ci}$ per experiment) (Amersham Pharmacia Biotech) uptake experiments were performed in the indicated media, and external ${ }^{45} \mathrm{Ca}^{2+}$ was removed by a rapid filtration over borosilicate glass fiber filters as described previously (Schnetkamp et al., 1991b); the washing medium contained (in mM): $140 \mathrm{KCl}, 80$ sucrose, $20 \mathrm{HEPES}, \mathrm{pH} 7.4,5 \mathrm{MgCl}_{2}$, and 1 EGTA. In some experiments ${ }^{45} \mathrm{Ca}^{2+}$ uptake was measured in choline chloride medium, in which case cells were washed and resuspended in choline chloride medium containing (in $\mathrm{mM}$ ): 150 choline chloride, 80 sucrose, $20 \mathrm{HEPES}, \mathrm{pH} 7.4$, and 0.05 EDTA. $\mathrm{NaCl}, \mathrm{KCl}$, $\mathrm{LiCl}$, and choline chloride were all SigmaUltra grade (Sigma-Aldrich). Protein content of cell samples was determined with the Bio-Rad protein assay (Bio-Rad Laboratories, Mississauga, Ontario).

\section{RESULTS}

\section{Cloning NCKX cDNAs from a chicken retinal cDNA library}

The main objective of this study was to identify and isolate the retinal cone-specific $\mathrm{Na}-\mathrm{Ca}$ exchanger. Our hypothesis was that cones, as has been shown for rods, would express a potassiumdependent $\mathrm{Na}-\mathrm{Ca}$ exchanger of the NCKX type. Therefore, we used the cDNA coding for transmembrane segments H6 to H11 region of bovine rod NCKX1 as a probe to screen chicken retinal cDNA libraries [characterized before by Bönigk et al. (1993)]. In earlier studies we identified this region as one that is the most highly conserved among mammalian rod NCKX1 proteins (Tucker et al., 1998a; Cooper et al., 1999). We identified 89 primary positive clones, from which 13 were randomly picked and further characterized; 12 of the 13 clones contained a full-length open reading frame. Three types of clones were detected: coding for three different proteins containing 662/663 residues (Type I, five clones), 651 residues (Type IIA, two clones), and 634 residues (Type IIB, five clones), respectively. Type IIA and IIB are identical, except for a 17 amino acid residue deletion in Type IIB, and are likely to represent two different splice variants of the same gene. The only polymorphism found in the chicken Type I clones was an Ala insertion at position 393 in three of five cDNA clones sequenced. To evaluate the presence of splice variants in the two NCKX cDNA types, 32 of the 89 primary positive chicken cDNA clones were screened by PCR, using primer sets specific for the two types of NCKX clones. Nine of the 32 clones (28\%) were positive for Type I, 14 (44\%) were positive for Type II, and 9 were negative for both sets, presumably incomplete clones or false positive clones. All positives for a particular primer set showed a PCR product of similar size; only the 17 amino acid deletion splice variant of the Type II NCKX could be detected on agarose gels (data not shown). From these results we conclude that other splice variants of both types of NCKX proteins are absent or very rare in the chicken retina.

All three different NCKX transcripts present in chick retina code for proteins of similar length when compared with rat brain NCKX2 (670 residues) but are significantly shorter than the mammalian rod NCKX proteins (1013-1216 residues). KyteDoolittle hydropathy analysis of the three types of chicken protein shows 12 hydrophobic segments arranged in two large sets of transmembrane-spanning segments (H1-5 and H6-11) and two large hydrophilic segments, one between $\mathrm{H} 0$ and $\mathrm{H} 1$ (proposed to be extracellular) and one between $\mathrm{H} 5$ and $\mathrm{H} 6$ (proposed to be cytosolic). This predicted topology is identical to that proposed for the mammalian rod NCKX sequences (Tucker et al., 1998a; Cooper et al., 1999) and for the rat brain NCKX2 sequence (Tsoi et al., 1998). The difference in length between our chicken NCKX proteins and mammalian rod NCKX proteins is mostly accounted for by the difference in length of the large hydrophilic segment between $\mathrm{H} 0$ and $\mathrm{H} 1$ ( $\sim 130$ residues compared with $\sim 445$ residues). We compared the sequence identity of the two sets of transmembrane spanning segments of our two types of chicken clones (Type IIA and IIB are identical within these regions) with those of bovine rod NCKX1 and rat brain NCKX2. The chicken Type I protein displays $89.8 \%$ identity with bovine rod NCKX1 and $81.7 \%$ with rat brain NCKX2. Conversely, the chicken type II proteins show $80.8 \%$ identity with bovine rod NCKX1 and $91.6 \%$ identity with rat brain NCKX2. The two types of chicken NCKX proteins show an overall amino acid identity of $58.5 \%$, but when only the two sets of transmembrane-spanning segments are considered this identity increases up to $82.6 \%$.

\section{Cloning of the Type II NCKX ortholog from human retina}

The chicken type I NCKX cDNA showed greatest homology to mammalian rod NCKX1. We earlier cloned the human retinal rod NCKX cDNA (Tucker et al., 1998a). Here, we describe molecular cloning of the human ortholog of chicken Type II retinal NCKX. A partial human NCKX Type II sequence was obtained by PCR amplification from human retinal cDNA. Using 5' and 3' RACE techniques, the full-length human cone NCKX cDNA, coding for a protein of 661 amino acid residues, was completed. The human Type II retinal NCKX showed 76.5 and $89.6 \%$ amino acid identity compared with chicken Type II retinal 


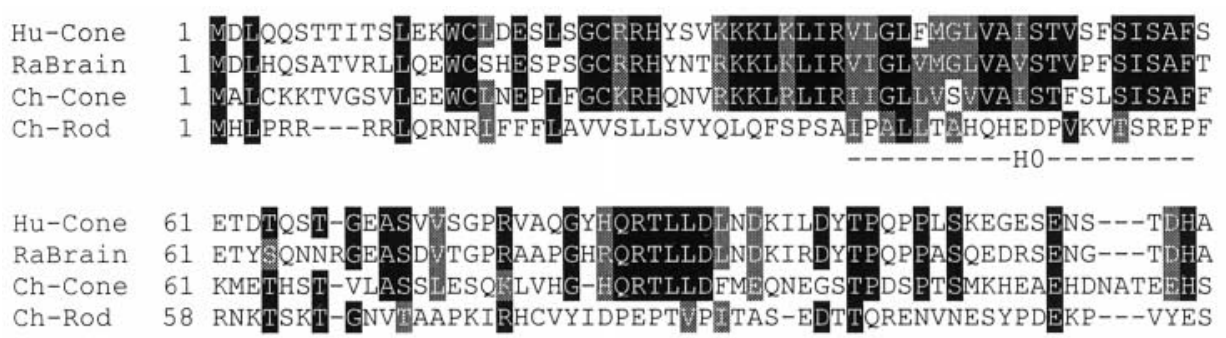

Hu-Cone

RaBrain

Ch-Cone

Ch-Rod

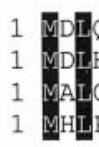
QQSTTITSLEKWCLDES
HQSATVRLLQEWSHES
CKKTVGSVLEWCINEP LSSCRRHYS
SPSGCRRHYN
PLFGCKRHEN SVKKLFLIRVLGLEMGLVAISTVSESISAFS
NTRKKLKLIRVIGLVMGLVAVSTVPFSISAFT PRR---RRLQRNRIFFFLAVVSLLSVYQLQFSPSAIPALITEHQHEDPVKVISREPF

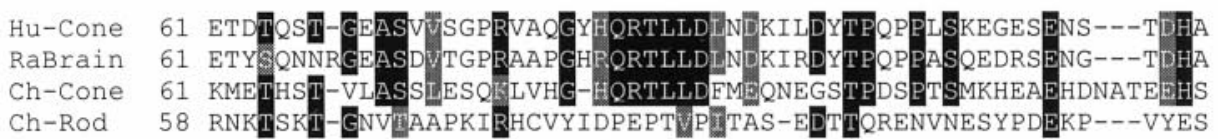

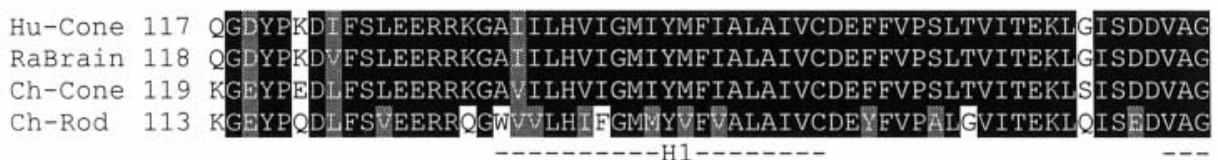

Hu-Cone 177

RaBrain 178

Ch-Cone 179

Ch-Rod 173

Hu-Cone 237

RaBrain 238

Ch-Cone 239

Ch-Rod 233
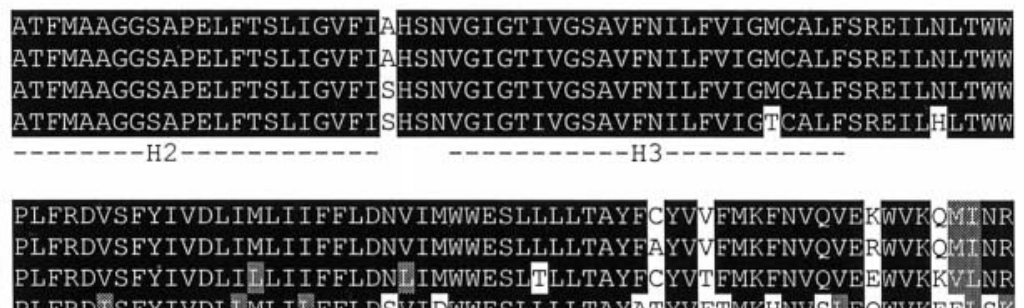

PLFRD FIT

-

WE

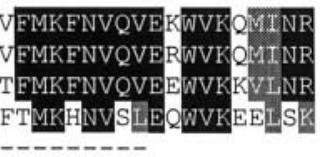

Hu-Cone 297

RaBrain 298

Ch-Cone 299

$\mathrm{Ch}-\mathrm{Rod}$
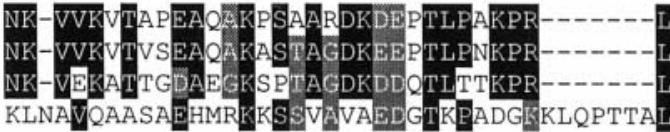

LQRGGSSASLHNSLMRNS I F LORGGSSASLHNSLMRNSIFO LQRGGSSASLHNSLMRNS I E

Hu-Cone 349

RaBrain 350

Ch-Cone 351

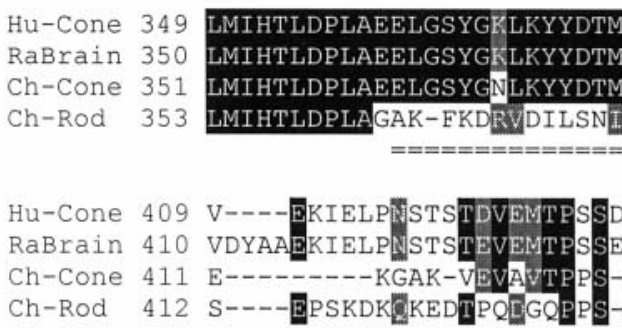

.

Ch-Rod 353
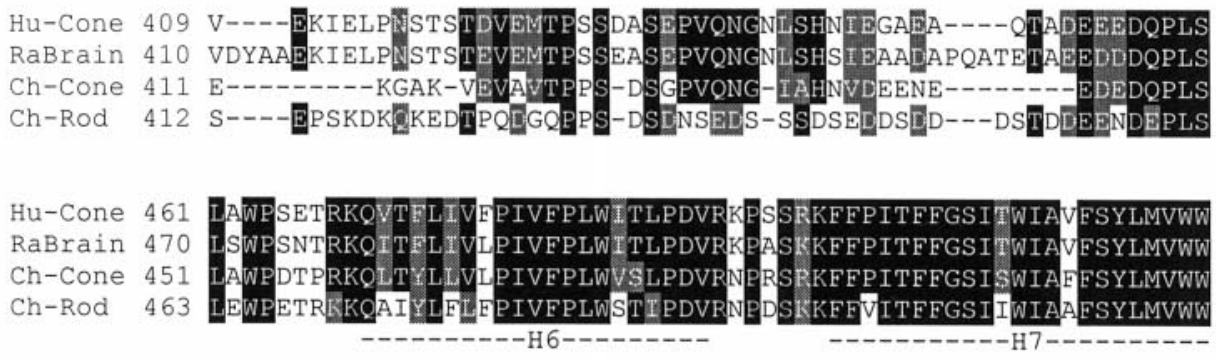

Hu-Cone 521

RaBrain 530

Ch-Cone 511

Ch-Rod 523

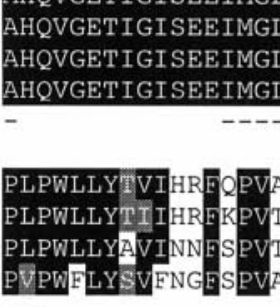

----------H7-

Hu-Cone 581 RaBrain 590 Ch-Cone 571 Ch-Rod 583 PVP

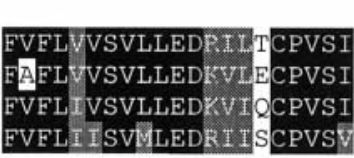

Figure 1. Comparison of chicken retinal rod and cone NCKX with rat brain NCKX2 and human retinal cone NCKX. Hu-Cone, Human cone NCKX; RaBrain, rat brain NCKX2 (Tsoi et al., 1998); Ch-Cone, chicken cone NCKX; Ch-Rod, chicken rod NCKX amino acid sequences. The putative transmembrane segments are underlined. Regions of alternative splicing for the two cone NCKX and brain NCKX2 are double underlined. Alignments were made using ClustalW 1.7 and Boxshade 3.21. Black boxed amino acid indicates identity in at least three proteins; gray boxed indicates a conserved amino acid substitution with at least two identical residues in the three other proteins. 

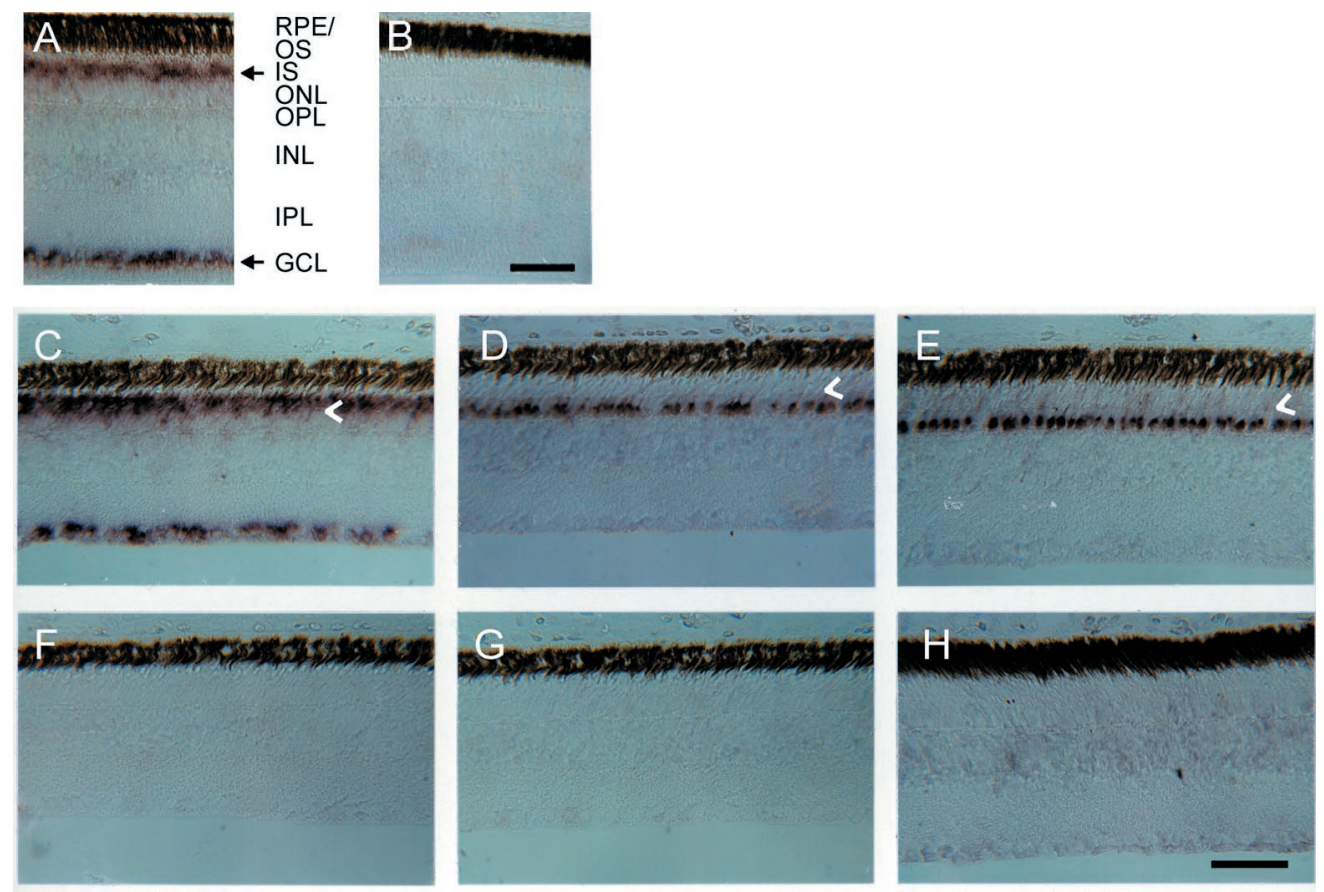

Figure 2. In situ hybridization in chicken retina. Photomicrographs of cross sections of the chicken central $(A, B)$ and peripheral $(C-H)$ retina, stained for cone NCKX $(A, C)$, rod NCKX $(D)$, and rhodopsin $(E)$ mRNA using their respective antisense riboprobe. Sense riboprobe for cone NCKX $(B, F)$, rod NCKX $(G)$, and rhodopsin $(H)$ mRNA were used as controls. RPE, Retinal pigment epithelium; $I S$, inner segments of photoreceptors; $O S$, outer segments of photoreceptors; $O N L$, outer nuclear layer; $O P L$, outer plexiform layer; $I N L$, inner nuclear layer; $I P L$, inner plexiform layer; $G C L$, ganglion cell layer. Arrowheads indicate the position of the outer limiting membrane $(O L M)$. Scale bar, $50 \mu \mathrm{m}$.

NCKX and rat brain NCKX2, respectively (Fig. 1). Chicken and human Type II NCKX and rat brain NCKX2 are spliced at exactly the same position, and the 17-residue-long splice-out shows only one amino acid change (the chicken clone has an Asn at position 7 compared with a Lys residue in the human and rat clones). The hydropathy plot places the alternatively spliced region in the large hydrophilic loop in the cytosol; the spliced-out region does not contain consensus sequences for kinases or other regulatory factors.

\section{Expression and distribution of NCKX mRNA in chicken retina}

We used in situ hybridization to localize Type I and II NCKX transcripts within the chicken retina. The chicken retina contains one type of rod and five types of cones. Rods are found at considerably lower density: one rod/three cones in the peripheral retina and one rod/five cones in central retina (Morris, 1970). Using whole-mount in situ hybridization, the spatial and temporal aspects of photoreceptor-specific molecules in the chick have been reported (Bruhn and Cepko, 1996): the center of the retina has a rod-free zone (area centralis) and contains all the cone types. Our Type II NCKX antisense riboprobe strongly labeled the inner segments of the majority of the photoreceptors (Fig. $2 A, C$ ); staining was equally intense in the central (Fig. $2 A$ ) as well as in the peripheral (Fig. $2 C$ ) retina. This staining pattern shows that retinal cones express Type II NCKX. Also, a clear staining of the cone-type NCKX was observed the retinal ganglion cell layer (GCL) in central and peripheral retina, but not all GCL cells were positive (Fig. $2 A, C$ ). The sense probes used as controls gave no specific staining (Fig. $2 B, F, H$ ). The full-length chicken Type I NCKX antisense riboprobe labeled a minority of the inner segments (Fig. 2D); staining was strong in cell bodies at the base of the outer nuclear layer (ONL) close to the outer plexiform layer (OPL) but tapered off toward the outer limiting membrane (OLM). Type I NCKX staining was much more pronounced in the peripheral retina compared with the central retina (data not shown), and the staining pattern was very similar to that observed for the rhodopsin antisense probe (Fig. 2E). From this we conclude that our Type I retinal chicken NCKX represents rod NCKX, consistent with the observation that chicken Type I showed highest homology to the mammalian rod NCKX (see above).

In further agreement with the correct identification of rod and cone NCKX within the chicken retina, we observed that the rod NCKX transcripts were found internal to the plane of the OLM of the retina, toward the OPL, which corresponds in shape and location to the rod photoreceptor inner segments. Cone NCKX transcripts in the photoreceptor region are located outside the OLM, more toward the outer segments (Fig. $2 A, C$ ), and staining for cone NCKX transcripts was more homogeneous than for rod NCKX transcripts. The above noted differences in the subcellular localization of rod and cone transcripts in the photoreceptor layer correspond well with observations that the nuclei of rods of gallinaceous birds lie in the lower half of the ONL, whereas most nuclei of the cones lie directly below the OLM (Ramon y Cajal, 1972; Mariani, 1987). The apical extensions of the cone nuclei, the inner segments, are located just external to the OLM, which corresponds well with the localization of the cone NCKX transcripts illustrated in Figure $2 A, C$.

\section{Northern blot analysis of rod and cone NCKX transcripts in chicken retina and brain}

We used Northern hybridization analysis to examine expression levels of the two chicken NCKX types in retina and brain because these are the two tissues in which NCKX transcripts have been demonstrated before (Reiländer et al., 1992; Tsoi et al., 1998). 
A

B
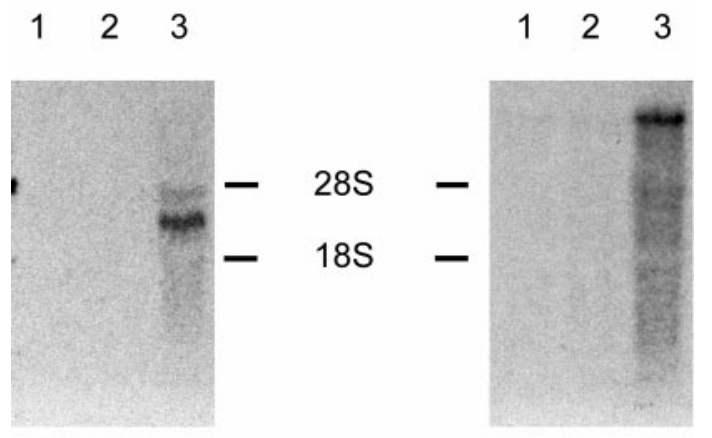

1
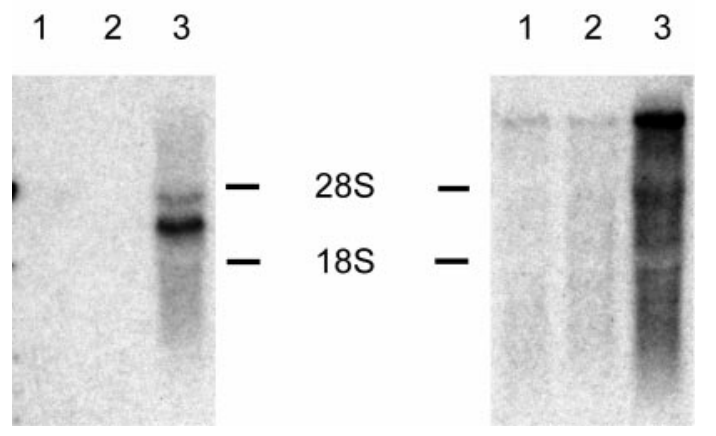

Figure 3. mRNA expression of NCKX in chicken retina and brain. Total RNA $(5 \mu \mathrm{g} /$ lane) was separated on a $1 \%$ formaldehyde/agarose gel. Northern hybridization was performed using $(A)\left[\alpha^{-32} \mathrm{P}\right] \mathrm{dCTP}$-labeled chicken retinal rod NCKX cDNA and $(B)$ chicken retinal cone NCKX cDNA as probes. The bottom panels show a longer exposure of $A$ and $B$. Lane 1, Total brain RNA (10-d-old chick); lane 2, total brain RNA (adult); lane 3, total retinal RNA (adult). The positions of the $28 \mathrm{~S}$ and $18 \mathrm{~S}$ ribosomal RNAs are indicated.

The Northern blot shows that the probe for chicken rod NCKX hybridized strongly to a retinal mRNA transcript of $\sim 6.5 \mathrm{~kb}$ (Fig. $3 A$ ), similar in size to those reported before for bovine (Reiländer et al., 1992) and human (Tucker et al., 1998b) rod NCKX1 poly $\left(\mathrm{A}^{+}\right)$-mRNA. The Northern blot also shows that the probe for chicken cone NCKX hybridized strongly to a single predominant retinal transcript of $\sim 10.5 \mathrm{~kb}$ and also to a similarly sized transcript in brain, albeit at a much lower level when compared with retina (Fig. 3B, bottom panel). We use human cone NCKX cDNA to probe a commercially available human normal brain blot containing mRNAs from the frontal lobe, temporal lobe, parietal lobe, occipital lobe, cerebellum, and lung and observed a hybridizing band at $10.5 \mathrm{~kb}$ of approximately equal intensity in all samples except for that from lung tissue (data not shown). In a separate Northern blot, we compared RNA isolated from human retina with human hippocampus RNA and observed a much stronger signal from human retina after hybridization with a human cone NCKX specific probe (data not illustrated), comparable to the results shown for chicken.

\section{Potassium-dependent $\mathrm{Na}-\mathrm{Ca}$ exchange of rod and cone NCKX expressed in insect cells}

We examined functional expression of the different NCKX proteins cloned here by measuring $\mathrm{Na}_{\mathrm{in}}$-dependent ${ }^{45} \mathrm{Ca}^{2+}$ uptake in
A.

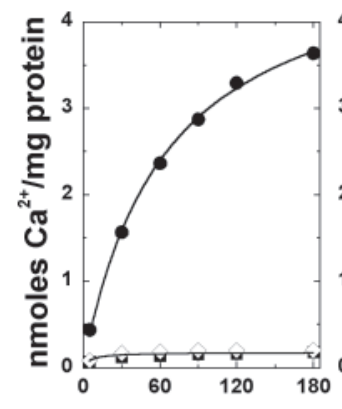

B.

C.

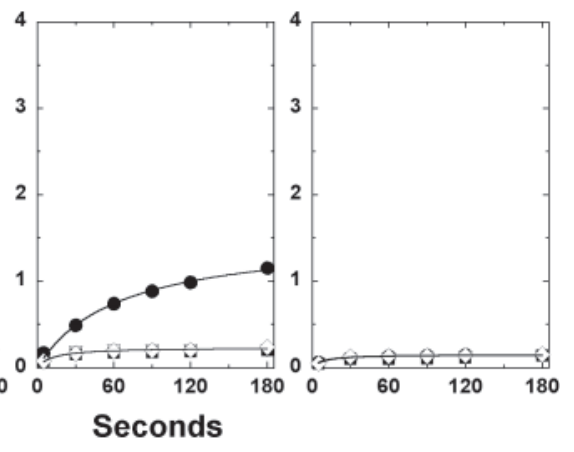

Figure 4. Potassium dependent ${ }^{45} \mathrm{Ca}^{2+}$ uptake in High Five cells transformed with the two chicken cone NCKX isoforms. ${ }^{45} \mathrm{Ca}^{2+}$ uptake was measured in sodium-loaded High Five cells expressing $(A)$ chicken cone NCKX splice variant, $(B)$ chicken full-length cone NCKX, and $(C)$ untransfected control cells $(C)$. Incubation media contained $80 \mathrm{~mm}$ sucrose, 20 mM HEPES (adjusted to $\mathrm{pH} 7.4$ with arginine), $5 \mu \mathrm{M}$ EDTA, 35 $\mu \mathrm{M} \mathrm{CaCl}, 1 \mu \mathrm{Ci}^{45} \mathrm{Ca}^{2+}$, and $150 \mathrm{mM} \mathrm{KCl}$ ( filled circles), or $150 \mathrm{mM}$ $\mathrm{NaCl}$ (open inverted triangles), or $150 \mathrm{~mm} \mathrm{LiCl}$ ( filled squares), or $150 \mathrm{~mm}$ $\mathrm{KCl}$ in the presence of $1 \mu \mathrm{M}$ monensin (open diamonds). The temperature was $25^{\circ} \mathrm{C}$.

High Five cells representing so-called reverse $\mathrm{Na}-\mathrm{Ca}$ exchange. These experiments take advantage of the well established property of NCKX proteins to mediate both calcium influx and calcium efflux dependent on the direction of the sodium gradient. Reverse $\mathrm{Na}-\mathrm{Ca}$ exchange has previously been described in outer segments isolated from bovine rod photoreceptors (Schnetkamp et al., 1989) and in cells transfected with cDNA from the fulllength dolphin retinal rod NCKX (Cooper et al., 1999). High Five cells were loaded with high sodium concentration with the use of the ionophore monensin as described in Materials and Methods; this method was used before to examine reverse $\mathrm{Na}-\mathrm{Ca}$ exchange in retinal rod outer segments (Schnetkamp et al., 1995).

We inserted the cDNAs of the various chicken and human NCKX cDNAs into a novel insect cell expression vector ( $\mathrm{Lu}$ et al., 1997; Farrell et al., 1998) and generated clonal cell lines after stable transfection. In a first set of experiments we used sodiumloaded High Five transformed with our different NCKX cDNAs to measure ${ }^{45} \mathrm{Ca}^{2+}$ uptake into cells suspended in a high potassium medium and compare it with ${ }^{45} \mathrm{Ca}^{2+}$ uptake into cells suspended in high sodium medium (Fig. 4). High potassium medium provides optimal support for potassium-dependent reverse $\mathrm{Na}-\mathrm{Ca}$ exchange, whereas high sodium inhibits reverse $\mathrm{Na}-\mathrm{Ca}$ exchange. No difference was observed in untransfected control cells between ${ }^{45} \mathrm{Ca}^{2+}$ uptake in high potassium medium and ${ }^{45} \mathrm{Ca}^{2+}$ uptake in high sodium medium (Fig. $4 C$ ). In contrast, ${ }^{45} \mathrm{Ca}^{2+}$ uptake in high potassium medium (filled circles) greatly exceeded ${ }^{45} \mathrm{Ca}^{2+}$ uptake in high sodium medium (inverted triangles) when cells transfected with either of the two splice variants of the chicken cone NCKX were examined (Fig. 4A,B). These results are consistent with ${ }^{45} \mathrm{Ca}^{2+}$ uptake via reverse $\mathrm{Na}-\mathrm{Ca}+\mathrm{K}$ exchange. To further support the notion that the large increase in ${ }^{45} \mathrm{Ca}^{2+}$ uptake in high potassium medium observed in sodiumloaded cells transfected with cone NCKX represents reverse $\mathrm{Na}-\mathrm{Ca}+\mathrm{K}$ exchange, two additional controls were performed. First, reverse Na-Ca exchange via the retinal rod NCKX in sodium-loaded cells is not supported when the external medium contains lithium without any potassium present; in contrast, reverse $\mathrm{Na}-\mathrm{Ca}$ exchange via the heart NCX1 operates independent of the presence of potassium in the external medium (Schnet- 


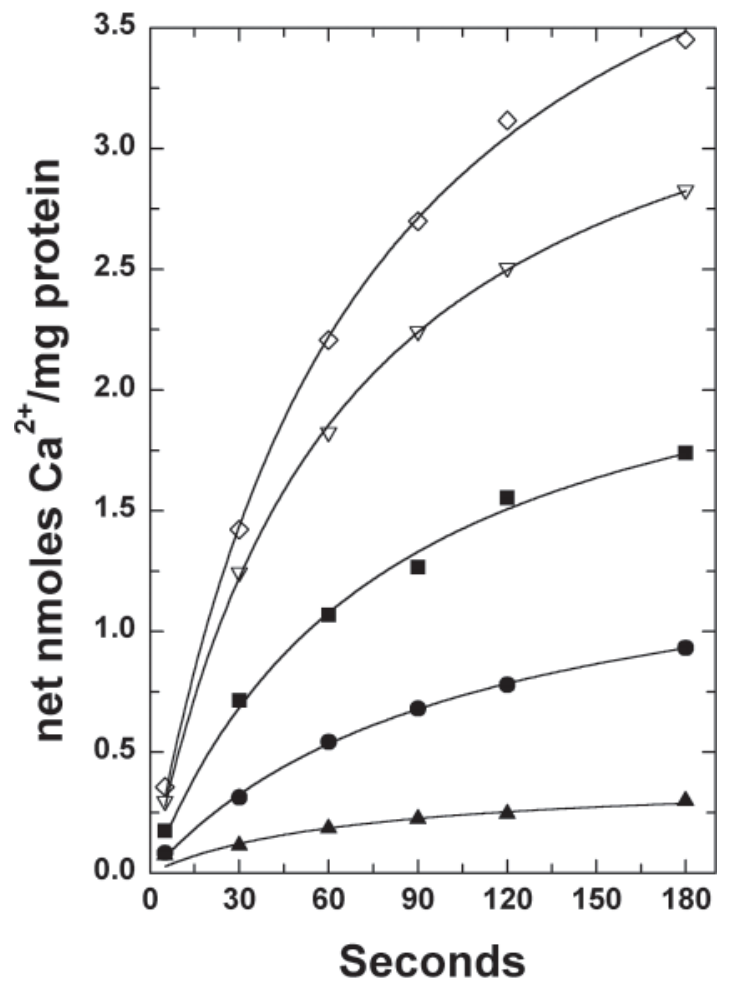

Figure 5. Net potassium-dependent ${ }^{45} \mathrm{Ca}^{2+}$ uptake in High Five cells transformed with the various chicken and human NCKX types. ${ }^{45} \mathrm{Ca}^{2+}$ uptake was measured in sodium-loaded High Five cells expressing chicken cone NCKX splice variant (open diamonds), human cone NCKX splice variant (open inverted triangles), human full-length cone NCKX ( filled squares), chicken full-length cone NCKX ( filled circles), and chicken rod NCKX ( filled triangles). Incubation media contained $80 \mathrm{~mm}$ sucrose, 20 mM HEPES (adjusted to $\mathrm{pH} 7.4$ with arginine), $5 \mu \mathrm{M}$ EDTA, $35 \mu \mathrm{M}$ $\mathrm{CaCl}_{2}, 1 \mu \mathrm{Ci}^{45} \mathrm{Ca}^{2+}$, and $150 \mathrm{~mm} \mathrm{KCl}$. The temperature was $25^{\circ} \mathrm{C}$.

kamp and Szerencsei 1991; Schnetkamp et al., 1991a; Cooper et al., 1999). Second, addition of alkali cation ionophores such as monensin or gramicidin to sodium-loaded High Five cells suspended in the high potassium medium should result in a complete release of internal sodium to the suspension medium and abolish reverse $\mathrm{Na}-\mathrm{Ca}$ exchange, similar to what we have shown before in the case of sodium-loaded rod outer segments (Schnetkamp et al., 1995). When the above two control conditions were applied to High Five cells transfected with either of the splice variants of the chicken cone exchanger, ${ }^{45} \mathrm{Ca}^{2+}$ uptake was reduced from the high value observed in potassium medium to the control level observed in the sodium medium (Fig. 4, square and diamond symbols). Neither the presence of different alkali cations in the suspension medium nor addition of monensin had any effect on ${ }^{45} \mathrm{Ca}^{2+}$ uptake in untransfected control cells (Fig. 4C). Similar experiments were performed with High Five cells transfected with the two splice variants of the human cone NCKX or with the chicken rod NCKX: significant ${ }^{45} \mathrm{Ca}^{2+}$ uptake above that in untransfected control cells was only observed in the potassium medium as illustrated here for the two chicken cone NCKXs (also see Fig. 5). We compared the net potassium-dependent component of ${ }^{45} \mathrm{Ca}^{2+}$ uptake observed in High Five cells transfected with the different rod and cone NCKX cDNAs described here (Fig. 5): the shorter splice variants of the two cone NCKXs consistently showed the highest potassium-dependent $\mathrm{Na}-\mathrm{Ca}$ exchange activity, whereas the lowest activity was observed for the chicken rod NCKX. A very similar ranking was obtained when

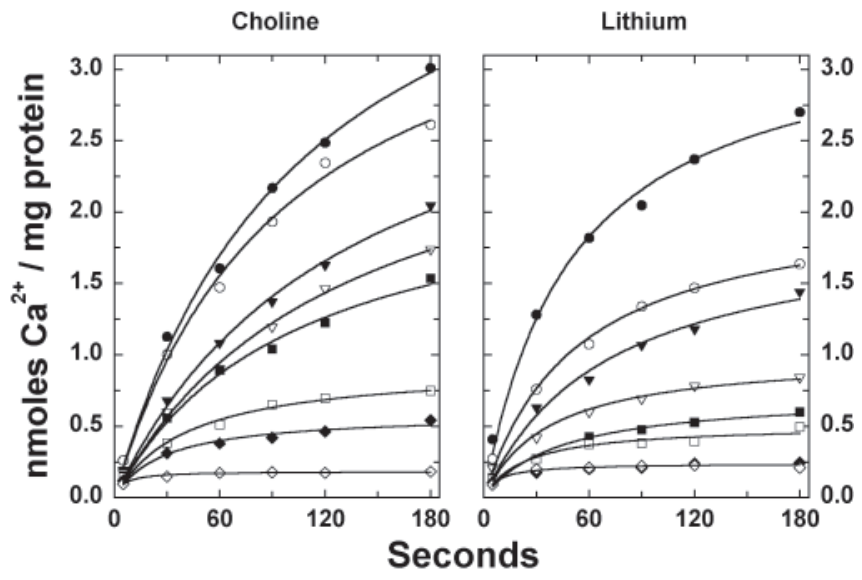

Figure 6. Potassium dependence of ${ }^{45} \mathrm{Ca}^{2+}$ uptake in High Five cells transformed with the human cone NCKX splice variant. ${ }^{45} \mathrm{Ca}^{2+}$ uptake was measured in sodium-loaded High Five cells expressing human cone NCKX splice variant as a function of external potassium concentration as described in the legend of Figure 4. Media contained either $150 \mathrm{~mm}$ choline chloride (left panel) or $150 \mathrm{~mm} \mathrm{LiCl}$ (right panel), or $150 \mathrm{~mm}$ $\mathrm{NaCl}$ (open diamonds in both panels). In the left-hand panel, $\mathrm{KCl}$ concentration was increased by iso-osmotic substitution of choline chloride to final concentrations of $150 \mathrm{~mm}$ ( filled circles), $20 \mathrm{~mm}$ (open circles), $5 \mathrm{~mm}$ (filled inverted triangles), $1 \mathrm{~mm}$ (open inverted triangles), $0.5 \mathrm{~mm}$ (filled squares), $0.1 \mathrm{~mm}$ (open squares), or no $\mathrm{KCl}$ (filled diamonds). In the right-hand panel, $\mathrm{KCl}$ concentration was increased by iso-osmotic substitution of $\mathrm{LiCl}$ to final concentrations of $150 \mathrm{~mm}$ (filled circles), $20 \mathrm{~mm}$ (open circles), $10 \mathrm{~mm}$ (filled inverted triangles), $5 \mathrm{~mm}$ (open inverted triangles), $2 \mathrm{~mm}$ (filled squares), $1 \mathrm{~mm}$ (open squares), or no $\mathrm{KCl}$ (filled diamonds). The temperature was $25^{\circ} \mathrm{C}$.

potassium-dependent $\mathrm{Na}-\mathrm{Ca}$ exchange activity was measured in other clonal cell lines or in transiently transfected cells (data not illustrated). Insect cells expressing chicken rod NCKX and cells expressing either of the two splice variants of chicken cone NCKX showed very similar levels of transcripts as detected on Northern blots of RNA isolated from several clonal lines (data not shown).

\section{Properties of the potassium binding site of different NCKX proteins}

The external potassium dependence of reverse $\mathrm{Na}-\mathrm{Ca}+\mathrm{K}$ exchange in isolated retinal rod outer segments varies markedly with the presence of other alkali cations in the medium (Schnetkamp and Szerencsei, 1991; Schnetkamp et al., 1995). Here, we examined the external potassium dependence of reverse $\mathrm{Na}-\mathrm{Ca}$ exchange in cells transfected with the different NCKX cDNAs in a medium in which either lithium chloride or choline chloride was the major constituent. We compared the results obtained with the different NCKX cDNAs with results obtained in isolated bovine retinal rod outer segments under identical sodium loading and medium conditions. Figure 6 illustrates the potassium dependence of ${ }^{45} \mathrm{Ca}^{2+}$ uptake in choline versus lithium medium for High Five cells expressing the short splice variant of human cone NCKX. The right-hand panel of Figure 6 shows that ${ }^{45} \mathrm{Ca}^{2+}$ uptake in sodium medium or in lithium medium without potassium was very similar and represents background ${ }^{45} \mathrm{Ca}^{2+}$ uptake observed in untransfected control cells. When the external potassium concentration was increased by iso-osmotic substitution of lithium chloride by potassium chloride, a gradual increase in both the rate and final level of ${ }^{45} \mathrm{Ca}^{2+}$ uptake was observed (halfmaximal at $\sim 15 \mathrm{~mm}$ potassium). As shown in Figure 4 , this potassium-dependent increase was only observed in cells trans- 
$\mathrm{LiCl}$

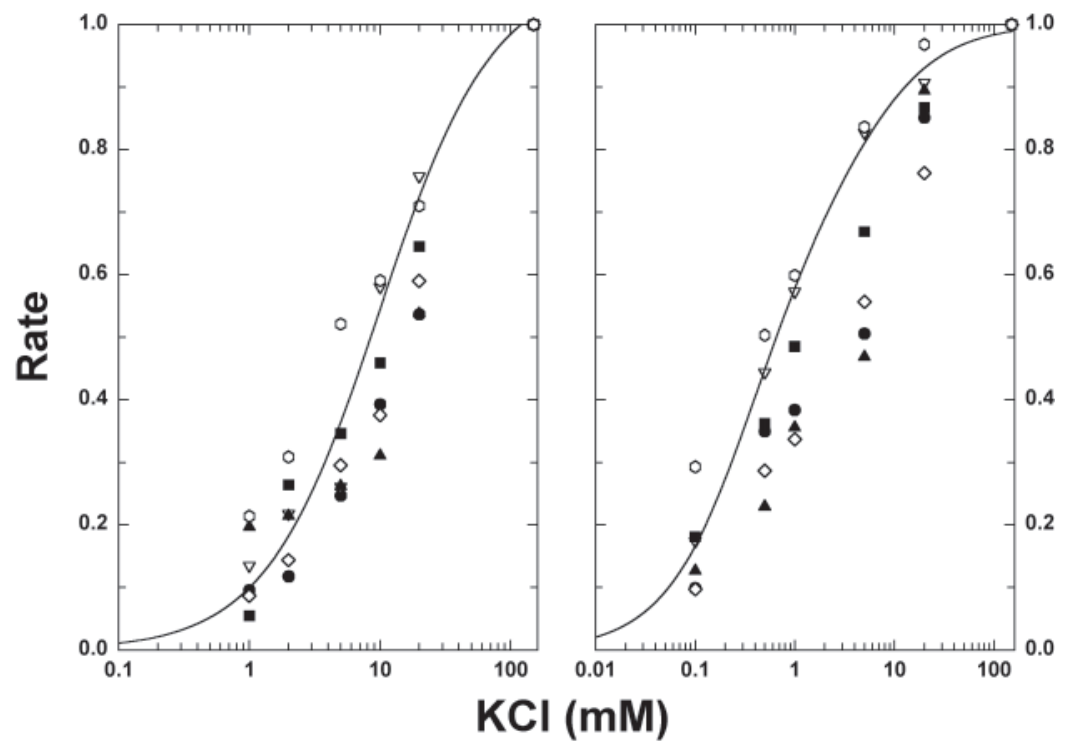

CholineCl
Figure 7. Comparison of the potassium dependence of ${ }^{45} \mathrm{Ca}^{2+}$ uptake in High Five cells transformed with different NCKX cDNAs used in this study. Initial rates of potassiumdependent ${ }^{45} \mathrm{Ca}^{2+}$ uptake (average of the first three time points) were obtained for cells transformed with the different NCKX cDNAs in either LiCl or choline chloride medium as illustrated in Figure 6. Left panel, Potassium dependence in $\mathrm{LiCl}$ medium. Right panel, Potassiumdependence in choline chloride medium. Potassium dependence was measured in both media for cells transformed with human full-length cone NCKX (open diamonds), chicken full-length cone NCKX (filled squares), chicken cone NCKX splice variant (open inverted triangles), human cone NCKX splice variant (filled circles), chicken rod NCKX ( filled triangles), or bovine rod outer segment NCKX (open hexagonals). fected with NCKX cDNAs and not in untransfected control cells. When the experiment was repeated with choline chloride replacing lithium chloride in the suspension medium (Fig. 6, left panel), a small but significant increase in ${ }^{45} \mathrm{Ca}^{2+}$ uptake was observed in potassium-free choline medium when compared with ${ }^{45} \mathrm{Ca}^{2+}$ uptake in sodium medium (compare filled diamonds with open diamonds). Furthermore, when the external potassium concentration was increased by iso-osmotic substitution of choline chloride by potassium chloride, both the rate and final level of ${ }^{45} \mathrm{Ca}^{2+}$ uptake increased at much lower potassium concentrations (halfmaximal at $\sim 2 \mathrm{~mm}$ potassium) when compared with those observed in lithium medium. A very similar pattern of potassiumdependent uptake in choline versus lithium medium was observed in isolated bovine rod outer segments and in High Five cells transfected with the other NCKX clones. The results are summarized in Figure 7. The initial rate of ${ }^{45} \mathrm{Ca}^{2+}$ uptake was represented by the average of the first three time points at 5, 30, and 60 sec, respectively, and the rate was normalized with respect to the maximal rate observed in full $150 \mathrm{~mm}$ potassium medium. Each of the six NCKX proteins tested showed a large (5- to 10-fold) shift in potassium dependence when uptake in choline medium was compared with that in lithium medium. Half-maximal activation of bovine rod outer segment NCKX and the two splice variants of chicken cone NCKX was observed at approximately twofold lower potassium concentrations (both in choline and in lithium medium) when compared with values observed for chicken rod or for the two splice variants of human NCKX. All six NCKX proteins showed a significant potassium-independent component when assayed in choline medium but not in lithium medium (data not shown).

\section{DISCUSSION}

A dynamic equilibrium between calcium influx via the cGMPgated channels and extrusion via the $\mathrm{Na}-\mathrm{Ca}+\mathrm{K}$ exchanger is thought to control the intracellular free calcium concentration in the outer segments of both retinal rods and cones. The presence of $\mathrm{Na}-\mathrm{Ca}$ exchange was previously demonstrated in salamander cone outer segments, and the time-constant of the light-induced decline of the exchanger current and changes in the intracellular free calcium concentration were shown to be much faster in cones when compared with rods (Nakatani and Yau, 1988, Nakatani and Yau, 1989; Hestrin and Korenbrot, 1990; Sampath et al., 1999). By analogy with rod photoreceptors, it was thought that a $\mathrm{Na}-$ $\mathrm{Ca}+\mathrm{K}$ exchanger operates in cone outer segments, but the identity of the cone exchanger had not yet been established, nor was it clear whether the cone exchanger belongs to the NCX or the NCKX family. In this report we used molecular cloning to isolate two splice variants of the gene products of both a chicken and human cone $\mathrm{Na}-\mathrm{Ca}+\mathrm{K}$ exchanger. In addition, we have cloned the cDNA of the chicken rod $\mathrm{Na}-\mathrm{Ca}+\mathrm{K}$ exchanger. We used in situ hybridization to identify the distinct rod and cone exchangers after localizing their transcripts to the inner segment of rods and cone photoreceptors, respectively.

\section{Rod and cone $\mathrm{Na}-\mathrm{Ca}+\mathrm{K}$ exchangers: sequence comparison}

The chicken rod or cone NCKX cDNAs code for surprisingly small proteins of 634-663 residues compared with the much larger NCKX proteins (1013-1216 residues) described previously from different mammalian rods (Reiländer et al., 1992; Tucker et al., 1998a; Cooper et al., 1999). The size difference makes a comparison of overall identity percentages difficult to interpret because the two large hydrophilic loops are of considerably different length and are quite variable, even when comparing the different mammalian rod NCKX sequences. When we limit the comparison to the two sets of proposed transmembrane spanning segments, chicken rod NCKX shows greatest similarity to mammalian rod NCKX, whereas chicken and human cone NCKX show greater identity to the similarly sized rat brain NCKX2 (Tsoi et al., 1998). When compared with the entire rat brain NCKX2 sequence, chicken rod NCKX shows 55.1\% identity, chicken cone NCKX shows $76.5 \%$ identity, and human cone NCKX shows $89.6 \%$ identity. Northern analysis showed that cone-type NCKX transcripts are considerably more abundant in human or chicken retina when compared with human or chicken brain, respectively (Fig. 3). When sequence comparison is limited to the proposed transmembrane spanning segments for all the vertebrate NCKX clones described to date, NCKX proteins fall clearly into two groups: the rod NCKX on the one hand and the cone and brain NCKX on the other hand (Fig. 8). The alignment 


\section{A}

Bo-Rod

Do-Rod

Hu-Rod

Ch-Rod

Hu-Cone

Ra-Brain

Ch-Cone

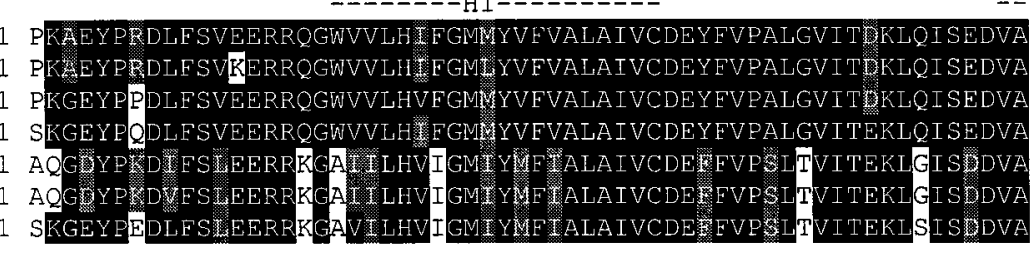

Bo-Rod
Do-Rod
Hu-Rod
Ch-Rod
Hu-Cone
Ra-Brain
Ch-Cone

Bo-Rod

Do-Rod

$\mathrm{Hu}-\mathrm{Rod}$

Ch-Rod

Hu-Cone

Ra-Brain

Ch-Cone
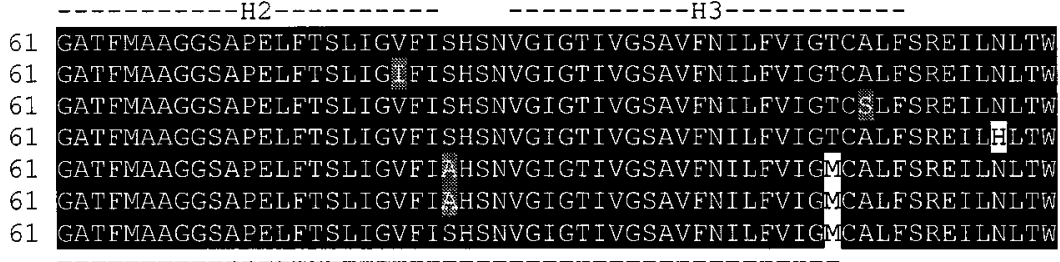

B

Bo - Rod

Do-Rod

$\mathrm{Hu}$-Rod

Ch-Rod

Hu-Cone

Ra-Brain

Ch-Cone

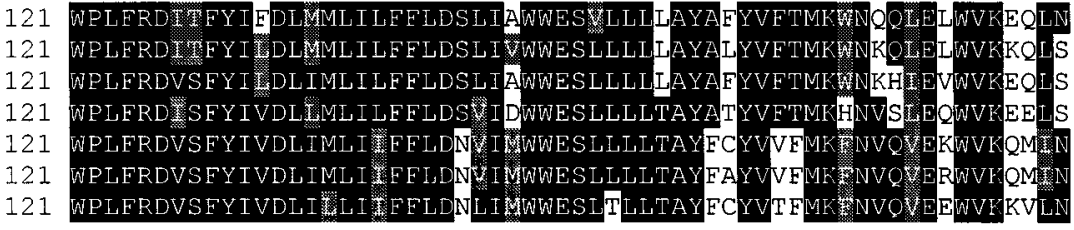

Figure 8. Comparison of four types of rod NCKX and three types of cone NCKX/ NCKX2 in the first $(A)$ and second $(B)$ transmembrane spanning segment. Bo-Rod, Bovine rod NCKX1 (Reiländer et al., 1992); Do-Rod, dolphin rod NCKX1 (Cooper et al., 1999); Hu-Rod, human rod NCKX1 (Tucker et al., 1998a); Ch-Rod, chicken rod NCKX; $\mathrm{Hu}$-Cone, human cone NCKX; Ra-Brain, rat brain NCKX2 (Tsoi et al., 1998); Ch-Cone, chicken cone NCKX amino acid sequences. Alignments were made using ClustalW 1.7 and Boxshade 3.21. The putative transmembrane segments are overlined, and the $\alpha$-repeat motifs as originally identified by Schwarz and Benzer (1997) are double underlined. Black boxed amino acid indicates identity in at least four proteins; gray boxed indicates a conserved amino acid substitution with at least three identical residues in the other sequences at the same position.

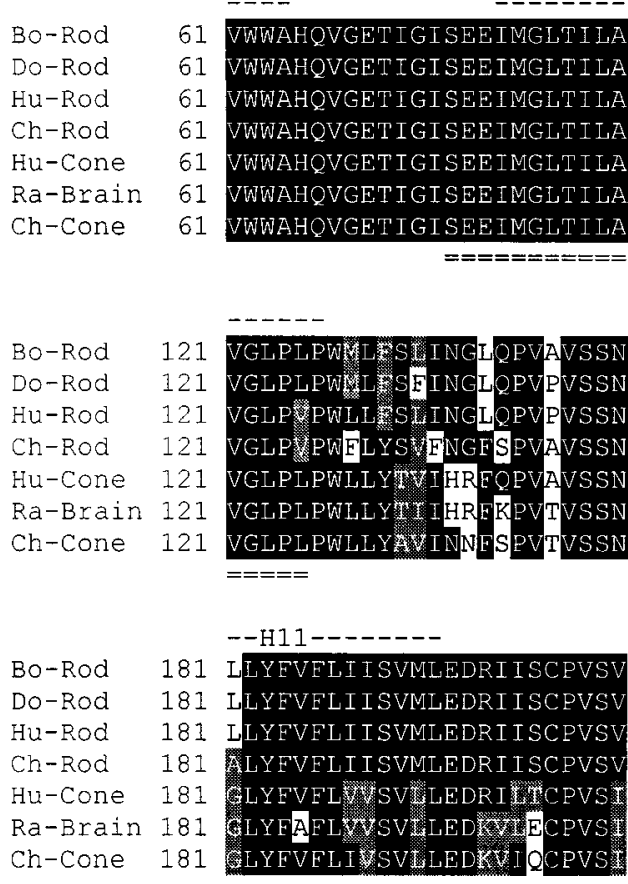


identifies several residues that could be used to distinguish between the two groups and may provide useful targets for mutagenesis if functional analysis would reveal significant differences in cation transport properties between the two groups (see below).

\section{Localization of NCKX transcripts in retina}

Our in situ hybridization results clearly show a colocalization of chicken rod NCKX and rhodopsin to the inner segment of rod photoreceptors, whereas cone NCKX transcripts were found in the cone inner segment layer and in a subpopulation of ganglion cells (Fig. 2). The extent of hybridization also shows that the majority of cones express the same gene product, but we cannot completely exclude the possibility that one of the five different types of chicken cones would express a different NCKX gene product. Rod NCKX1 and the rod cGMP-gated channels are found to be associated in bovine rod outer segments (Bauer and Drechsler, 1992). Nonsensory cGMP-gated channels have been identified in retinal ganglion cells by whole-cell patch-clamp studies (Ahmad et al., 1994; Thompson, 1997; Kawai and Sterling, 1999). This may suggest that NCKX proteins can be found in cells expressing cGMP-gated channels and play a crucial role in extruding calcium that enters cells via the nonspecific cGMP-gated channels.

\section{Cone NCKX cDNAs code for potassium-dependent Na-Ca exchangers}

Functional analysis of rod NCKX proteins after heterologous expression has previously yielded some apparently conflicting results. In our hands, neither the full-length bovine nor human rod NCKX1 yielded $\mathrm{Na}-\mathrm{Ca}$ exchange activity in a number of different heterologous systems, whereas the full-length dolphin rod NCKX1 yielded potassium-dependent $\mathrm{Na}-\mathrm{Ca}$ exchange after transfection into HEK293 (Cooper et al., 1999). In contrast, Navangione et al. (1997) used transient transfection of HEK293 cells with full-length bovine NCKX1 and observed Na-Ca exchange currents that did not depend on potassium; these authors suggest that potassium dependence may be conferred on the NCKX1 protein by a yet to be identified accessory component/ protein. In this study we used stable transfection into insect High Five cells, and we observed with all five NCKX cDNAs described here that $\mathrm{Na}_{\mathrm{in}}$-dependent calcium uptake (reverse $\mathrm{Na}-\mathrm{Ca}$ exchange) was completely dependent on external potassium and internal sodium (Figs. 4, 5). Moreover, we observed a large shift in potassium affinity in isolated bovine rod outer segments when reverse $\mathrm{Na}-\mathrm{Ca}$ exchange in choline medium was compared with that in lithium medium. When we tested High Five cells transfected with our different NCKX clones for this distinct feature of the potassium binding site, we observed in all cases a 5- to 10-fold decrease in potassium dependence when calcium uptake in choline medium was compared with that in lithium medium; in choline medium, the $K_{\mathrm{m}}$ for potassium ranged between 0.5 and 3 $\mathrm{mm}$, whereas in lithium this value ranged between 7 and $15 \mathrm{~mm}$ (Figs. 6, 7). Similar observations were made with the full-length dolphin NCKX1, with a deletion mutant of bovine NCKX1 in which most of the two large hydrophilic loops was removed, and with an NCKX paralog cloned from Caenorhabditis elegans (Szerencsei et al., 2000). From these results we conclude that the potassium binding site conferring potassium dependence on the $\mathrm{Na}-\mathrm{Ca}+\mathrm{K}$ exchanger is an integral part of the NCKX protein and does not require any additional factors or proteins.

All NCKX proteins tested in our lab in the High Five cell system shared a very similar potassium dependence with that observed in isolated bovine rod outer segments. In contrast, the maximal calcium transport activity observed for reverse $\mathrm{Na}-\mathrm{Ca}$ exchange varied significantly among the different NCKX proteins. Net potassium-dependent calcium uptake was lowest for chicken rod NCKX (0.3 nmol calcium/mg protein), comparable to values between 0.4 and $0.6 \mathrm{nmol}$ calcium $/ \mathrm{mg}$ protein observed in another study for full-length dolphin rod NCKX1 and a deletion mutant of bovine NCKX1 (Szerencsei et al., 2000). In contrast, the short splice variant of the human and chicken cone NCKX showed severalfold higher calcium uptake activities of $\sim 3 \mathrm{nmol}$ calcium/mg protein (Fig. 5). The high activity of these cone NCKX clones was consistently observed in different clonal cell lines and in transiently transfected cells (data not illustrated). This could merely reflect different protein levels (although transcript levels appeared comparable) or different amounts of properly processed protein. However, it is tempting to speculate that the difference in transport capacity may represent differences in turnover number for rod and cone NCKX, respectively, and may reflect the differences observed for calcium fluxes in cones versus rods. Profound differences in calcium permeation have been observed for the cGMP-gated cation channels in rod and cone photoreceptors, respectively; the fraction of the dark current that is carried by calcium ions is much greater in cone cGMP-gated channels compared with rod cGMP-gated channels (Perry and McNaughton, 1991; Frings et al., 1995; Picones and Korenbrot, 1995; Dzeja et al., 1999). Furthermore, direct measurements of light-induced changes in outer segment calcium concentration revealed that the calcium concentration in the cone outer segment varies over a 75-fold dynamic range in red-sensitive cones, a value more than three times greater than in rods of the same species, with time constants three to six times faster than in rods (Sampath et al., 1998, 1999). The faster time constant of light-induced changes in calcium could also be interpreted to indicate that the calcium buffer capacity of rod outer segments significantly exceeds that in cone outer segments. The calcium-sensitive sites within the phototransduction cascade are likely to be influenced more profoundly in cones during exposure to steady light than in rods and therefore may reflect a more powerful modulation of calcium-sensitive processes in cones than in rods (Yau, 1994), as has been established for the ligand sensitivity of cGMP-gated ion channels (Miller et al., 1994; Rebrik and Korenbrot, 1998). Further studies on the rod and cone NCKX may elucidate whether functional differences between the two exchangers contribute significantly to the observed differences in rod and cone physiology.

\section{REFERENCES}

Ahmad I, Leinders-Zufall T, Kocsis JD, Shepherd GM, Zufall F, Barnstable CJ (1994) Retinal ganglion cells express a cGMP-gated cation conductance activatable by nitric oxide donors. Neuron 12:155-165.

Bauer PJ, Drechsler M (1992) Association of cyclic GMP-gated channels and $\mathrm{Na}^{+}-\mathrm{Ca}^{2+}-\mathrm{K}^{+}$exchangers in bovine retinal rod outer segment plasma membranes. J Physiol (Lond) 451:109-131.

Blaustein MP, Lederer WJ (1999) Sodium/calcium exchange: its physiological implications. Physiol Rev 79:763-854.

Bönigk W, Altenhofen W, Müller F, Dose A, Illing M, Molday RS, Kaupp UB (1993) Rod and cone photoreceptor cells express distinct genes for cGMP-gated channels. Neuron 10:865-877.

Breitschopf H, Suchanek G (1996) Nonradioactive in situ hybridization application manual, Ed 2, pp 136-140. Mannheim, Germany: Boehringer Mannheim.

Bruhn SL, Cepko CL (1996) Development of the pattern of photoreceptors in the chick retina. J Neurosci 16:1430-1439.

Cervetto L, Lagnado L, Perry RJ, Robinson DW, McNaughton PA 
(1989) Extrusion of calcium from rod outer segments is driven by both sodium and potassium gradients. Nature 337:740-743.

Cooper CB, Winkfein RJ, Szerencsei RT, Schnetkamp PPM (1999) cDNA cloning and functional expression of the dolphin retinal rod $\mathrm{Na}-\mathrm{Ca}+\mathrm{K}$ exchanger NCKX1: comparison with the functionally silent bovine NCKX1. Biochemistry 38:6276-6283.

Dzeja C, Hagen V, Kaupp UB, Frings S (1999) $\mathrm{Ca}^{2+}$ permeation in cyclic nucleotide-gated channels. EMBO J 18:131-144.

Farrell PJ, Lu ML, Prevost J, Brown C, Behie L, Iatrou K (1998) High-level expression of secreted glycoproteins in transformed lepidopteran insect cells using a novel expression vector. Biotechnol Bioeng 60:656-663.

Frings S, Seifert R, Godde M, Kaupp UB (1995) Profoundly different calcium permeation and blockage determine the specific function of distinct cyclic nucleotide-gated channels. Neuron 15:169-179.

Gray-Keller MP, Detwiler PB (1994) The calcium feedback signal in the phototransduction cascade of vertebrate rods. Neuron 13:849-861.

Haase W, Friese W, Gordon RD, Muller H, Cook NJ (1990) Immunological characterization and localization of the $\mathrm{Na}^{+} / \mathrm{Ca}^{2+}$-exchanger in bovine retina. J Neurosci 10:1486-1494.

Hestrin S, Korenbrot JI (1990) Activation kinetics of retinal cones and rods: response to intense flashes of light. J Neurosci 10:1967-1973.

Kawai F, Sterling P (1999) AMPA receptor activates a G-protein that suppresses a cGMP-gated current. J Neurosci 19:2954-2959.

Kim TS, Reid DM, Molday RS (1998) Structure-function relationships and localization of the $\mathrm{Na} / \mathrm{Ca}-\mathrm{K}$ exchanger in rod photoreceptors. J Biol Chem 273:16561-16577.

Korenbrot JI (1995) $\mathrm{Ca}^{2+}$ flux in retinal rod and cone outer segments: differences in $\mathrm{Ca}^{2+}$ selectivity of the cGMP-gated ion channels and $\mathrm{Ca}^{2+}$ clearance rates. Cell Calcium 18:285-300.

Lagnado L, Cervetto L, McNaughton PA (1988) Ion transport by the $\mathrm{Na}-\mathrm{Ca}$ exchange in isolated rod outer segments. Proc Natl Acad Sci USA 85:4548-4552.

Lu M, Farrell PJ, Johnson R, Iatrou K (1997) A baculovirus (Bombyx mori nuclear polyhedrosis virus) repeat element functions as a powerful constitutive enhancer in transfected insect cells. J Biol Chem 272:30724-30728.

Mariani AP (1987) Neuronal and synaptic organization of the outer plexiform layer of the pigeon retina. Am J Anat 179:25-39.

McNaughton PA, Cervetto L, Nunn BJ (1986) Measurement of the intracellular free calcium concentration in salamander rods. Nature 322:261-263.

Miller JL, Picones A, Korenbrot JI (1994) Differences in transduction between rod and cone photoreceptors: an exploration of the role of calcium homeostasis. Curr Opin Neurobiol 4:488-495.

Morris VB (1970) Symmetry in a receptor mosaic demonstrated in the chick from the frequencies, spacing and arrangement of the types of retinal receptor. J Comp Neurol 140:359-398.

Nakatani K, Yau KW (1988) Calcium and light adaptation in retinal rods and cones. Nature 334:69-71.

Nakatani K, Yau KW (1989) Sodium-dependent calcium extrusion and sensitivity regulation in retinal cones of the salamander. J Physiol (Lond) 409:525-548.

Navangione A, Rispoli G, Gabellini, N, Carafoli E (1997) Electrophysiological characterization of ionic transport by the retinal exchanger expressed in human embryonic kidney cells. Biophys J 73:45-51.

Perry RJ, McNaughton PA (1991) Response properties of cones from the retina of the tiger salamander. J Physiol (Lond) 443:561-587.

Picones A, Korenbrot JI (1995) Permeability and interaction of $\mathrm{Ca}^{2+}$ with cGMP-gated ion channels differ in retinal rod and cone photoreceptors. Biophys J 69:120-127.

Ramon y Cajal S (1972) The retina of birds. In: The structure of the retina (Thorpe SA, Glickstein M, eds), pp 76-92. Springfield, IL: Charles C. Thomas.

Rebrik TI, Korenbrot JI (1998) In intact cone photoreceptors, a $\mathrm{Ca}^{2+}$ dependent, diffusible factor modulates the cGMP-gated ion channels differently than in rods. J Gen Physiol 112:537-548.

Reid DM, Friedel U, Molday RS, Cook NJ (1990) Identification of the sodium-calcium exchanger as the major ricin-binding glycoprotein of bovine rod outer segments and its localization to the plasma membrane. Biochemistry 29:1601-1607.

Reiländer H, Achilles A, Friedel U, Maul G, Lottspeich F, Cook NJ (1992) Primary structure and functional expression of the $\mathrm{Na} / \mathrm{Ca}$, K-exchanger from bovine rod photoreceptors. EMBO J 11:1689-1695.

Sampath AP, Matthews HR, Cornwall MC, Fain GL (1998) Bleached pigment produces a maintained decrease in outer segment $\mathrm{Ca}^{2+}$ in salamander rods. J Gen Physiol 111:53-64.

Sampath AP, Matthews HR, Cornwall MC, Bandarchi J, Fain GL (1999) Light-dependent changes in outer segment free- $\mathrm{Ca}^{2+}$ concentration in salamander cone photoreceptors. J Gen Physiol 113:267-277.

Schaeren-Wiemers N, Gerfin-Moser A (1993) A single protocol to detect transcripts of various types and expression levels in neural tissue and cultured cells: in situ hybridization using digoxigenin-labelled cRNA probes. Histochemistry 100:431-440.

Schnetkamp PPM, Szerencsei RT (1991) Effect of potassium ions and membrane potential on the $\mathrm{Na}-\mathrm{Ca}-\mathrm{K}$ exchanger in isolated intact bovine rod outer segments. J Biol Chem 266:189-197.

Schnetkamp PPM, Basu DK, Szerencsei RT (1989) $\mathrm{Na}^{+}-\mathrm{Ca}^{2+}$ exchange in bovine rod outer segments requires and transports $\mathrm{K}^{+}$. Am J Physiol 257:C153-C157.

Schnetkamp PPM, Li XB, Basu DK, Szerencsei RT (1991a) Regulation of free cytosolic $\mathrm{Ca}^{2+}$ concentration in the outer segments of bovine retinal rods by $\mathrm{Na}-\mathrm{Ca}-\mathrm{K}$ exchange measured with fluo-3. I. Efficiency of transport and interactions between cations. J Biol Chem 266:22975-22982.

Schnetkamp PPM, Szerencsei RT, Basu DK (1991b) Unidirectional $\mathrm{Na}^{+}, \mathrm{Ca}^{2+}$, and $\mathrm{K}^{+}$fluxes through the bovine rod outer segment Na-Ca-K exchanger. J Biol Chem 266:198-206.

Schnetkamp PPM, Tucker JE, Szerencsei RT (1995) $\mathrm{Ca}^{2+}$ influx into bovine retinal rod outer segments mediated by $\mathrm{Na}^{+} / \mathrm{Ca}^{2+} / \mathrm{K}^{+}$exchange. Am J Physiol 269:C1153-1159.

Schwarz EM, Benzer S (1997) Calx, a Na-Ca exchanger gene of Drosophila melanogaster. Proc Natl Acad Sci USA 94:10249-10254.

Szerencsei RT, Tucker JE, Cooper CB, Winkfein RJ, Farrell PJ, Iatrou K, Schnetkamp PPM (2000) Minimal domain requirement for cation transport by the potassium-dependent $\mathrm{Na} / \mathrm{Ca}-\mathrm{K}$ exchanger: comparison with a NCKX paralog from Caenorhabditis elegans. J Biol Chem, 275:669-676

Thompson SH (1997) Cyclic GMP-gated channels in a sympathetic neuron cell line. J Gen Physiol 110:155-164.

Tsoi M, Rhee KH, Bungard D, Li XF, Lee SL, Auer RN, Lytton J (1998) Molecular cloning of a novel potassium-dependent sodium-calcium exchanger from rat brain. J Biol Chem 273:4155-4162.

Tucker JE, Winkfein RJ, Cooper CB, Schnetkamp PPM (1998a) cDNA cloning of the human retinal rod $\mathrm{Na}-\mathrm{Ca}+\mathrm{K}$ exchanger: comparison with a revised bovine sequence. Invest Ophthalmol Vis Sci 39:435-440.

Tucker JE, Winkfein RJ, Murthy SK, Friedman JS, Walter MA, Demetrick DJ, Schnetkamp PPM (1998b) Chromosomal localization and genomic organization of the human retinal rod $\mathrm{Na}-\mathrm{Ca}+\mathrm{K}$ exchanger. Hum Genet 103:411-414.

Yau KW (1994) Phototransduction mechanism in retinal rods and cones. The Friedenwald Lecture. Invest Ophthalmol Vis Sci 35:9-32.

Yau KW, Nakatani K (1984) Electrogenic Na-Ca exchange in retinal rod outer segment. Nature 311:661-663. 